\title{
Replication fork stalling and cell cycle arrest in UV-irradiated Escherichia coli
}

\author{
Christian J. Rudolph, Amy L. Upton, and Robert G. Lloyd ${ }^{\mathbf{1}}$ \\ Institute of Genetics, University of Nottingham, Queen's Medical Centre, Nottingham NG7 2UH, United Kingdom
}

\begin{abstract}
Faithful duplication of the genome relies on the ability to cope with an imperfect template. We investigated replication of UV-damaged DNA in Escherichia coli and found that ongoing replication stops for at least 15-20 min before resuming. Undamaged origins of replication (oriC) continue to fire at the normal rate and in a DnaA-dependent manner. UV irradiation also induces substantial DnaA-independent replication. These two factors add substantially to the DNA synthesis detected after irradiation and together mask the delay in the progression of pre-existing forks in assays measuring net synthesis. All DNA synthesis after UV depends on DnaC, implying that replication restart of blocked forks requires DnaB loading and possibly the entire assembly of new replisomes. Restart appears to occur synchronously when most lesions have been removed. This raises the possibility that restart and lesion removal are coupled. Both restart and cell division suffer long delays if lesion removal is prevented, but restart can occur. Our data fit well with models invoking the stalling of replication forks and their extensive processing before replication can restart. Delayed restart avoids the dangers of excessive recombination that might result if forks skipped over lesion after lesion, leaving many gaps in their wake.
\end{abstract}

[Keywords: Fluorescent microscopy; BrdU labelling; excision repair; DnaA; DnaB; DnaC]

Supplemental material is available at http://www.genesdev.org.

Received November 8, 2006; revised version accepted January 29, 2007.

At the root of genomic instability lies the raw fact that evolution is concerned with survival rather than with exact transmission of the genome. Organisms survive and reproduce because they exploit repair systems to reduce or eliminate lesions from the DNA and use surveillance mechanisms (checkpoints) to make sure cells progress through the cell cycle only when it is appropriate to do so. Thus, the $\mathrm{G}_{1}-\mathrm{S}$ transition checkpoint inhibits initiation of DNA replication in eukaryotes if there are lesions in the template. The delay provides time for repair activities to restore the template, after which replication might proceed unhindered. Without such coordination, there is increased risk of mutation, genomic instability, and cell death (Myung et al. 2001).

There appears to be no $\mathrm{G}_{1}-\mathrm{S}$ checkpoint in bacteria. In an early model based on studies of the DNA synthesized in UV-irradiated Escherichia coli cells, Rupp and Howard-Flanders (1968) proposed that replication forks simply proceed past the damage and resume synthesis downstream, leaving gaps that are then filled in by RecAmediated recombination (Fig. 1A, i). They estimated that replication is delayed no more than $\sim 10 \mathrm{sec}$ per lesion. This post-replication repair model had one major drawback. It was held almost as dogma that the priming of

${ }^{1}$ Corresponding author.

E-MAIL bob.lloyd@nottingham.ac.uk; FAX 44115823013.

Article is online at http://www.genesdev.org/cgi/doi/10.1101/gad.417607. leading strand synthesis is restricted to oriC (Courcelle and Hanawalt 2003). So, how could replication resume downstream from a lesion? A possible solution emerged recently. Heller and Marians (2006) showed that synthesis of the leading strand could be initiated de novo at fork structures, at least in vitro, raising the possibility that leading strand synthesis could in fact restart downstream from a lesion.

In the intervening period, Meneghini and Hanawalt (1975) suggested that a lesion in the leading strand template blocks fork progression whereas a lesion in the lagging strand template does not. The lagging strand polymerase simply skips an Okazaki fragment, leaving a gap. This model has been strongly supported by in vitro as well as in vivo data showing that lesions in the template can indeed disrupt the coupled synthesis of leading and lagging strands (Higuchi et al. 2003; Pages and Fuchs 2003; McInerney and O'Donnell 2004). In vivo, replication of the leading strand was delayed for a substantial period (Pages and Fuchs 2003). This delay conflicts with the Rupp and Howard-Flanders model but fits with data showing that the rate of DNA synthesis drops dramatically immediately after UV irradiation (Khidhir et al. 1985; Courcelle et al. 2005, 2006). Synthesis recovers in wild-type cells but not in excision repairdefective uvrA mutants, except at low UV doses, indicating that nucleotide excision repair is important for recovery. 
A

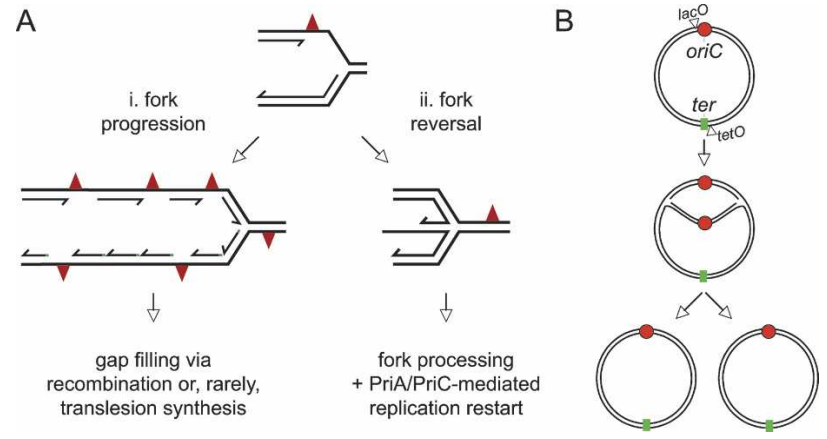

Figure 1. DNA replication and replication restart after UV irradiation in E. coli. (A) Models of replication restart: (i) A fork skips over lesions (red triangles) leaving gaps in the nascent strands. (ii) A fork stalls at a leading strand block and reverses to form a Holliday-junction structure that is then processed to allow restart. (B) Diagram illustrating initiation and termination of chromosome replication. The open triangles indicate the positions of the lacO240 and tetO arrays used.

But how does replication resume if the lesion is masked by the stalled replisome or cannot be repaired because the template is unwound? Higgins et al. (1976) and Fujiwara and Tatsumi (1976) presented evidence that blocked forks reverse in mammalian cells to form a Holliday-junction structure, which can then be exploited to restart replication (Fig. 1A, ii). In recent years, the idea that extensive fork processing might be associated with replication restart has gained momentum (McGlynn and Lloyd 2002; Michel et al. 2004). It stands in sharp contrast to the original model of Rupp and Howard-Flanders (1968).

In this study, we provide evidence that lesions induced by UV delay ongoing replication quite markedly and that initiation of new rounds of replication together with the triggering of UV-induced synthesis can mask this delay. Our data also show that ongoing replication recovers eventually and that this recovery depends on loading of the replicative helicase and, to a large extent, on lesion removal while replication is delayed.

\section{Results}

Replication in E. coli initiates when DnaA protein binds the single origin of replication (oriC), opens the duplex, and facilitates transfer of DnaB helicase from a DnaB:DnaC complex to each of the template strands. This leads to the assembly of two replisomes, which then move in opposite directions around the chromosome (Marians 1992). Duplication of the entire chromosome is achieved when two forks meet at the terminus (ter) (Fig. 1B). The cell cycle is completed when the chromosomes segregate and division occurs (Lau et al. 2003; Sherratt 2003; Wang et al. 2005).

\section{Chromosome replication in UV-irradiated cells}

To investigate the effect of UV on DNA replication and chromosome segregation we used a strain in which ori- gin and terminus areas of the chromosome were tagged with $1 a c O$ and tet $O$ arrays, respectively (Fig. 1B), carrying a plasmid encoding LacI-eCFP (enhanced cyan fluorescent protein) and TetR-eYFP (enhanced yellow fluorescent protein) repressors to decorate these arrays (Lau et al. 2003). We first addressed the question of replication fork progression. If a fork meets a pyrimidine dimer, fast reinitiation downstream from the lesion, as predicted by Rupp and Howard-Flanders (1968), should enable the cell to replicate the array near the terminus region. However, if replication is stalled and the replication fork has to be processed in a time-consuming way, cells should remain in a state in which the origin array may have been duplicated, but the terminus array remains as a single focus.

Cells were irradiated with $30 \mathrm{~J} / \mathrm{m}^{2} \mathrm{UV}$, which has been estimated to induce 1200 lesions per chromosome, which translates to one lesion every $8 \mathrm{~kb}$ per single strand (Appendix I in Materials and Methods; Sedgwick 1975; Courcelle et al. 2006). At least $80 \%$ of the cells survived the exposure. Without irradiation, cells had morphologies typical of exponential growth in broth: $13.2 \%$ showed two foci for the origin region, $33.1 \%$ had three, $50.4 \%$ had four, and $3.3 \%$ had five. Most (87.6\%) showed one focus for the terminus region, the remainder had two (Fig. 2A; Lau et al. 2003). The overall ratio of origin to terminus foci was $3: 1$. By $30 \mathrm{~min}$ after irradiation, all cells were filamentous and there was little sign of any increase in terminus foci. The number of discrete origin foci per cell was also largely unchanged but these showed an increase in intensity (Supplementary Fig. S1). This effect became even more striking by $60 \mathrm{~min}$, but the numbers of terminus foci were still quite low: $82.2 \%$ had one to four origin foci, with an average of 2.9 , but the majority $(98 \%)$ had only one to two terminus foci, with an average of 1.6 (Fig. 2A). The increase in intensity of the origin foci was a feature of $81 \%$ of the filaments at this stage. By $90 \mathrm{~min}$, the high intensity of the origin foci had largely disappeared, but the number of discrete origin foci per filament had increased substantially. The mean overall was 12.5 , with $75 \%$ showing seven to 17 and $9.7 \%$ showing $19-23$. Furthermore, these foci were spreading out along the filaments (Fig. 2A,B). This number is in line with the origin firing occurring roughly every $30 \mathrm{~min}$, which corresponds to a measured doubling time of $30.4 \mathrm{~min}$ for the nonirradiated cells. These data demonstrate that UV irradiation does not prevent origin firing, which is consistent with previous studies (Billen 1969). More importantly, they show that the origin continues to fire at the normal rate in the majority of cells, which excludes the existence of a eukaryote-like $G_{1}-S$ transition checkpoint. There is no evidence that UV induces DnaA-dependent oriC firing.

In contrast, the number of terminus foci per filament at 90 min remained low, with an overall average of 2.4 (Fig. 2A,B). By 120-150 min, the pattern had changed dramatically. The number of terminus foci increased to an average of 4.6 per filament overall and in $45.3 \%$ of cases ranged from five to 13 . Furthermore, these had interspersed with the origin foci (Fig. 2B, right panel). From 
Rudolph et al.

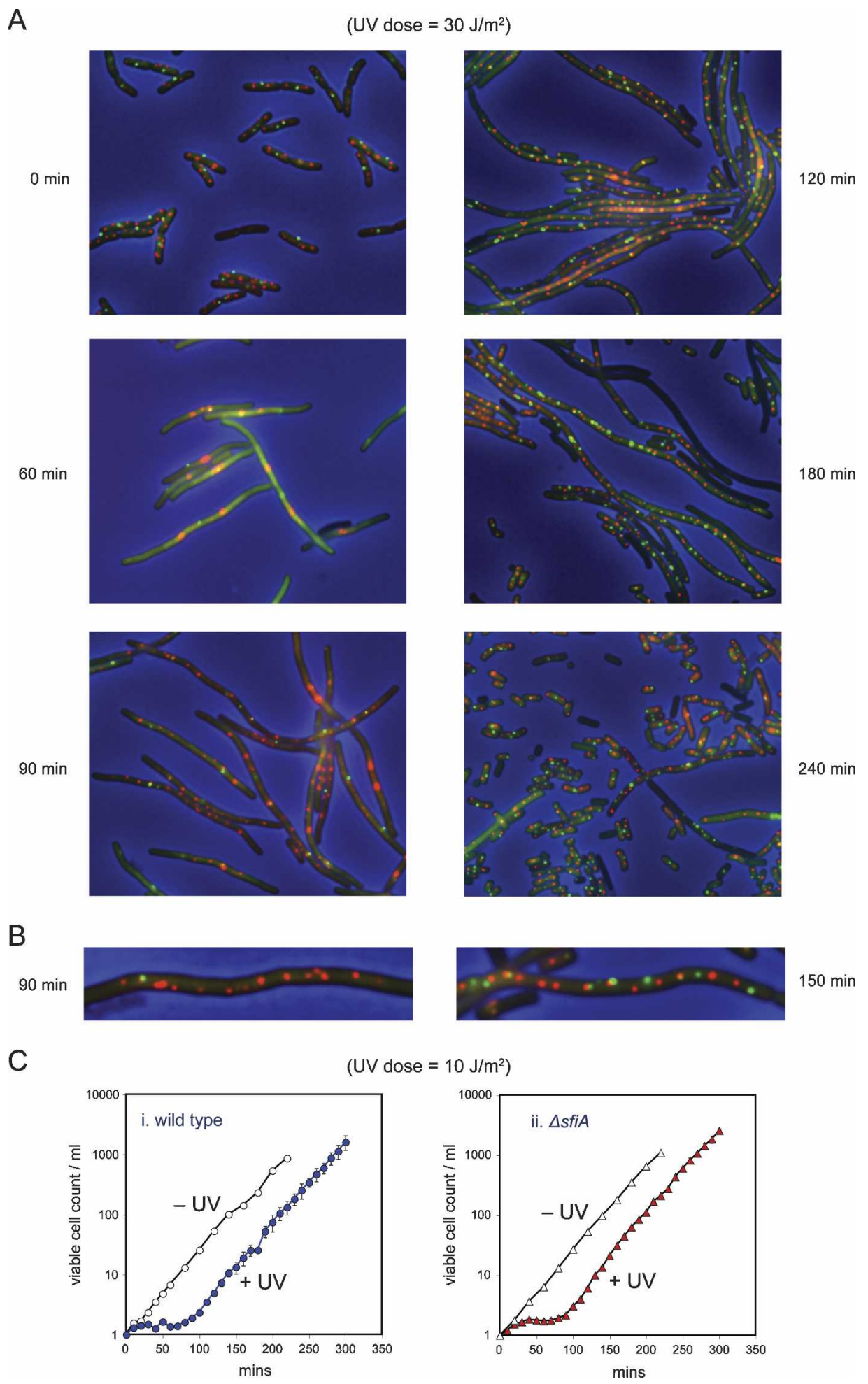

Figure 2. Effect of UV on cell cycle progression. (A) Fluorescence microscopy showing replication of origin (red foci) and terminus (green foci) areas of the chromosome (combined phase contrast and fluorescence images are shown). The strain used was APS345. The incubation time after irradiation is indicated. $(B)$ Enlargements of filaments from a repeat of the experiment in $A$. $(C)$ Viable cell replication following irradiation. The strains used were MG1655 (wild type) and N5209 (sfiA11). Data for the irradiated cells are the mean $\left({ }_{ \pm} \mathrm{SE}\right)$ of three experiments. The data for the nonirradiated cells are the mean of two experiments that gave almost identical values. 
180 min onward, more and more normal-sized cells began to appear, and by $240 \mathrm{~min}$ there were few filaments remaining. By this time cells became quite short, indicating they were entering stationary phase. The ratio of origin to terminus foci was reduced to $1.6: 1$. We repeated the experiment using a UV dose of $10 \mathrm{~J} / \mathrm{m}^{2}$, which increases the interlesion distance per strand to $\sim 24 \mathrm{~kb}$. A very similar response was seen, except that the increase in the intensity of the origin foci was less dramatic, and recovery occurred earlier (Supplementary Fig. S1).

One explanation for these data would be that ongoing DNA replication is blocked for a period in UV-irradiated cells, preventing any increase in the number of terminus foci. During this delay, oriC continues firing at about the rate in nonirradiated cells, with the result that foci for the region near the origin accumulate in situ. However, the blocked forks do ultimately recover, or are rescued, enabling the newly replicated DNA molecules, and hence the origin foci, to separate. Finally, the chromosome is duplicated and the cells divide.

The cells used might filament and delay septation abnormally because of the arrays and plasmid. (Note: Repressors were induced only in the samples of irradiated cells taken for analysis.) We therefore examined the time taken for irradiated cells lacking these elements to resume division after UV. Division was delayed by 60-70 min after a dose of $10 \mathrm{~J} / \mathrm{m}^{2}$ (Fig. 2C, panel i). This delay was also observed by time-lapse microscopy (data not shown). An almost identical delay was observed in a sfiA mutant lacking the SOS-induced division inhibitor (Fig. 2C, panel ii; data not shown). These observations indicate that SOS-induced cell filamentation is not the major reason why division takes so long to resume. They support the idea that replication of the terminus, and hence chromosome segregation, is much delayed.

To investigate whether the increase in the origin signal is indeed due to replication, we repeated the experiment with a dnaC7 temperature-sensitive derivative. DnaC binds DnaB and is necessary for loading DnaB both during replication initiation at oriC and during rescue of stalled forks by PriA/PriC (Marians 2004). DnaC was inactivated by shifting the cells to $42^{\circ} \mathrm{C}$ directly after irradiation with $10 \mathrm{~J} / \mathrm{m}^{2}$. The cells filamented, but in sharp contrast to what was seen with $d n a C^{+}$cells there was almost no change in the number of origin and terminus foci (Supplementary Fig. S2). This confirms that replication is responsible for the increase in the number of foci for the origin region.

\section{Replication after UV irradiation requires loading of the DnaB replicative helicase}

To gain a more quantitative measure of how UV affects new initiation at oriC, we measured incorporation of $\left[{ }^{3} \mathrm{H}\right]$ thymidine in both wild-type control and temperature-sensitive $d n a A$ and $\operatorname{dnaC}$ strains shifted to $42^{\circ} \mathrm{C}$ immediately after irradiation. In the control, the rate of incorporation after UV was reduced to an extent consis- tent with synthesis being delayed for some 10-15 min (Fig. 3A; Khidhir et al. 1985; Courcelle et al. 2003). In mock-irradiated dnaC7 cells, incorporation continued for a time before reaching a plateau consistent with synthesis by all existing replication forks coming to an end. However, hardly any incorporation was detected after UV (Fig. 3A). Thus, even though UV lesions are not expected to block advance of DnaB, it would appear that little or no synthesis is possible without the means to load the replicative helicase. This implies that existing replisomes are unable to continue past any significant number of pyrimidine dimers. The fact that we did not detect residual synthesis associated with fork progression to the first blocking lesion likely reflects the delay between irradiation and addition of label. It reinforces the idea that the existing forks proceed past very few lesions, and indeed many may halt at the first lesion encountered. However, this result alone does not exclude the possibility that replication continues with only slight hindrance, as suggested by Heller and Marians (2006), since assembly of new replisomes downstream from lesions may be rapid.

\section{UV irradiation induces DnaA-independent DNA synthesis}

As with dnaC, nonirradiated dnaA46 cells incorporated thymidine to an extent consistent with completion of existing rounds of replication (Fig. 3B). However, incorporation was significantly greater in the irradiated cells, as also reported by Jonczyk and Ciesla (1979), contrasting sharply with the dnaC7 result (Fig. 3A). Essentially identical results were obtained using strains carrying temperature-sensitive dnaA167 or dnaA204 alleles (Fig. 3C). Since all synthesis after UV irradiation depends on DnaC, we assume the synthesis induced by UV and detected in irradiated $d n a A$ temperature-sensitive cells requires DnaB loading. We suspect it reflects the establishment of new replication forks via the initiation of stable DNA replication, which is known to be DnaA-independent and triggered by DNA damage (Kogoma 1997). This would be consistent with the fact that, after 70-min incubation, the irradiated cells have incorporated more than twice the amount of $\left[{ }^{3} \mathrm{H}\right]$ thymidine into acid-precipitable material than the nonirradiated cells. Without new forks, it is difficult to see how this extra synthesis could be achieved. Excision repair is highly unlikely to be sufficient given the number of lesions introduced and the known lengths of the repair tracts. Indeed, we found that this UV-induced synthesis is detectable in an excision repair-defective mutant (data not shown). However, there is clearly less synthesis after UV in the dnaA strains than in the wild type (Fig. 3B,C). Taken together, these data indicate that DnaA-dependent oriC firing and UV-induced, DnaA-independent synthesis are responsible for a substantial fraction of the synthesis seen after irradiation of wild-type cells. They are also consistent with the evidence that the origin can fire when the terminus cannot replicate (Fig. 2). 

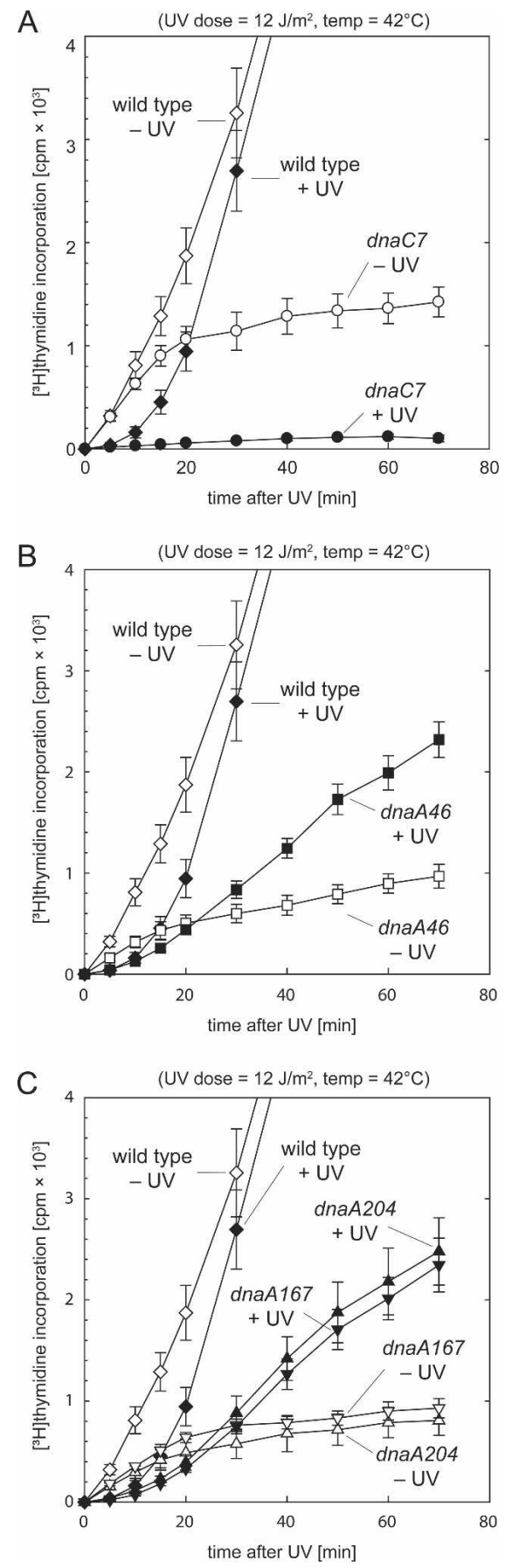

Figure 3. Effect of UV on DNA synthesis in dnaA46 and dnaC7 strains. (A) $\left[{ }^{3} \mathrm{H}\right]$ thymidine incorporation in wild-type (N1141) and dnaC7 (AU1080) cells. Data are the mean $( \pm$ SE) of three experiments. $(B)\left[{ }^{3} \mathrm{H}\right]$ thymidine incorporation in wild-type (N1141) and dnaA46 (AU1068) cells. Data are the mean $( \pm$ SE) of four to five experiments. The data for the wild type are reproduced from $A$ for comparison. $(C)\left[{ }^{3} \mathrm{H}\right]$ thymidine incorporation in wild-type (N1141), dnaA167 (AU1093), and dnaA204 (AU1094) cells. Data are the mean $( \pm \mathrm{SE})$ of three to four experiments. The data for the wild type are reproduced from $A$ for comparison.
5-Bromo-2'-deoxyuridine (BrdU) labeling reveals a transient delay in progression of all pre-existing replication forks

The incorporation of $\left[{ }^{3} \mathrm{H}\right]$ thymidine provides no indication of whether there is disproportionate synthesis at any particular chromosomal location. To gain a more detailed picture of where synthesis is taking place, we labeled new DNA with BrdU, digested the chromosome with NotI, and separated the fragments by PFGE before probing for BrdU. In an exponential culture of nonirradiated cells, fragments should incorporate BrdU to a level reflecting fork distribution in the asynchronous cell population and the length of each fragment. This is what we observed; signal intensity in the fragments increased as predicted over a 15 -min period (Fig. 4B).

A very different picture emerged when the cells were irradiated before adding BrdU. The signal detected during the first 15-20 min was much reduced for all fragments (Fig. 4B). This indicates a delay in the progression of all replication forks, as suggested by the reduced rate of thymidine incorporation (Fig. 3).

Furthermore, the bands containing DNA fragments located at or close to oriC appeared to give an even stronger signal than expected at early times when compared with those containing only oriC-distal fragments (Fig. 4A,B, green arrows). This is most easily observed with the band labeled I. This band reflects BrdU incorporation into three NotI fragments-two located near oriC and one $\sim 1.9 \mathrm{Mbp}$ away; i.e., $\sim 85 \%$ of the distance to ter (Fig. $4 \mathrm{~A}$ ). Because these are relatively small $(\sim 30-40 \mathrm{~kb})$ and well separated from other fragments, they could be resolved using different gel running conditions. Resolution of these fragments showed an early and increased level of BrdU labeling of the two closest to oriC. Labeling of the third fragment beginning $1.89 \mathrm{Mbp}$ away from ori $\mathrm{C}$ is much delayed (Fig. 4D). We quantified the BrdU in these fragments and calculated the ratio of the label per kilobase in the origin-proximal and origin-distal regions. Without UV, the ratio averaged 1.7:1. With UV, it increased gradually to a maximum of $16: 1$ at $35 \mathrm{~min}$, before reducing to $4.9: 1$ at $40 \mathrm{~min}$. This quantification confirms that UV delays progression of pre-existing forks but does not prevent oriC from firing. Because of their large size $(\geq 200 \mathrm{~kb})$, and a difference of only $2-7 \mathrm{~kb}$ between them, the individual fragments contributing to the two intermediate bands labeled in Figure 4A cannot be resolved by PFGE to allow similar quantification of the BrdU incorporated into origin-proximal and origin-distal regions. The one unique DNA fragment (the slowest-migrating band indicated by arrow in Fig. 4A) covers so much of the chromosome that it is uninformative.

To determine whether the increased labeling of the most origin-proximal fragments is due to DnaA-dependent oriC firing, we conducted the same experiment with a dnaA46 strain, shifting the cells to $42^{\circ} \mathrm{C}$ directly after irradiation. All fragments showed BrdU incorporation after an initial delay, similar to that seen with wildtype cells (Fig. 4C). This confirms our $\left[{ }^{3} \mathrm{H}\right]$ thymidine incorporation data showing that replication is not com- 
A

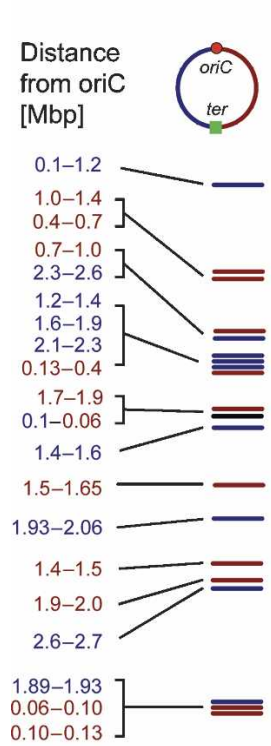

B wild type
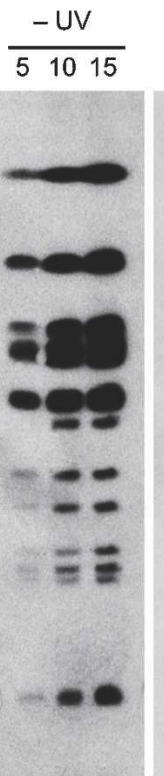

\section{C dnaA46}

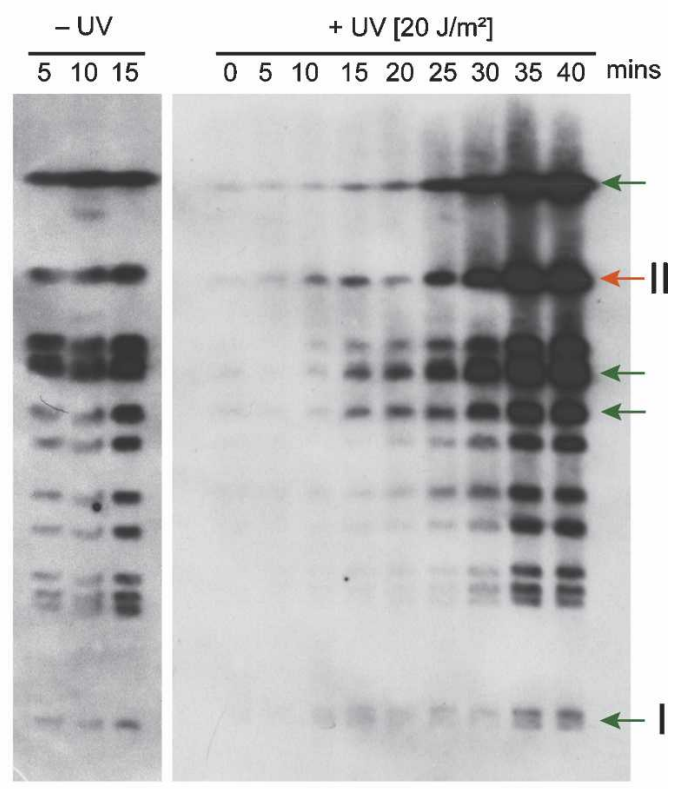

E

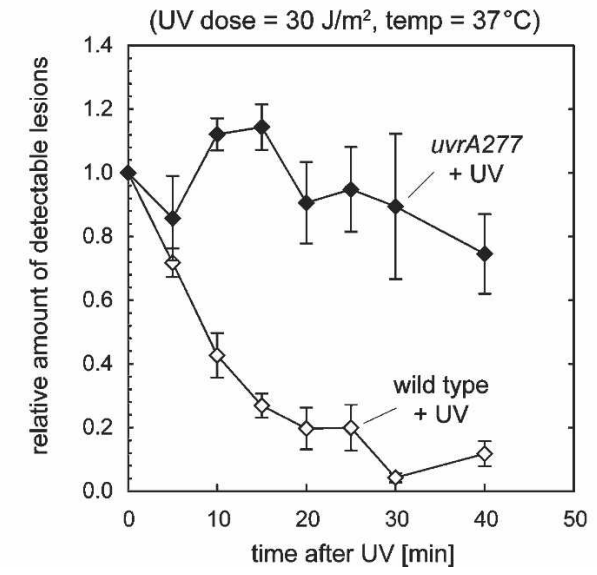

Figure 4. Replication and repair of UV-irradiated DNA. (A) Schematic NotI restriction pattern of the E. coli chromosome. The distance from oriC to each end of the fragments is indicated. Fragments clockwise and counterclockwise of oriC are shown in red and blue, respectively. $(B)$ Fluorograph showing BrdU incorporation into the chromosome of wild-type strain MG1655 $\pm U V$. Originproximal bands labeled intensively are identified with green arrows. (C) BrdU incorporation pattern in dnaA46 strain AU1054. To inhibit oriC firing, cells were shifted to $42^{\circ} \mathrm{C}$ directly before adding BrdU. $(D)$ Resolution of band I identified in $B .(E)$ Pyrimidine dimer removal from strains MG1655 (wild type) and N4280 (uvrA).

pletely blocked. However, the disproportionate labeling of the oriC-proximal fragments, especially those contributing to band I, was no longer evident. The weak labeling of fragments contributing to band I in the nonirradiated cells is consistent with the absence of origin firing at $42^{\circ} \mathrm{C}$. These results indicate that after irradiation new rounds of replication are initiated from oriC in a normal DnaA-dependent manner. We could find no conclusive evidence that the UV-induced and DnaA-independent synthesis revealed by $\left[{ }^{3} \mathrm{H}\right]$ thymidine incorporation (Fig. 3B) is initiated at sites like the oriMs within oriC described by Kogoma (1997). However, we cannot rigorously exclude the possibility as there is some indication of disproportionate labeling at early times of fragments within three of the slower-migrating bands identified with green arrows in Figure 4C, one of which spans the ori $C$ region. We were unable to sufficiently resolve these bands for a more quantitative analysis. If the oriMs do fire, the lack of early labeling of band I would suggest that the resulting synthesis does not extend far in the clockwise direction. The band identified with an orange arrow and labeled II in Figure 4C shows perhaps a clearer indication of disproportionate signal at early times. Two NotI fragments migrate in this position, both of which would be replicated by the fork moving clockwise from oriC (Fig. 4A). So, it is possible that UV may induce initiation of DNA replication in either or both of these fragments. 
Taken together with the results shown in Figures 2 and 3 , these data indicate that DNA synthesis by preexisting replisomes is brought to a halt following the introduction of UV lesions into the DNA. The origin of replication keeps on firing and, after a delay, replication can be detected at all sites around the chromosome. The precise location of the additional UV-induced, DnaA-independent synthesis (Fig. 3B) is not clear from the BrdU labeling. However, all the replication depends on DnaC, which indicates that it is carried out by new replisomes assembled via DnaB loading. Little or none of it is carried out by replisomes present at the time of irradiation.

\section{DNA synthesis is reduced drastically in the absence} of excision repair and origin firing

Can we estimate how long ongoing replication is delayed? Rupp and Howard-Flanders (1968) used $\left[{ }^{3} \mathrm{H}\right]$ thymidine accumulation into the DNA to conclude that replication forks are delayed by no more than $\sim 10 \mathrm{sec}$ per lesion (Heller and Marians 2006). However, we have shown there is continued origin firing in UV-irradiated cells and also a significant amount of UV-induced synthesis. The accumulation of $\left[{ }^{3} \mathrm{H}\right]$ thymidine into DNA is therefore likely to seriously underestimate the delay. But the Rupp and Howard-Flanders estimate was based on studies with excision repair-defective uvrA cells. Therefore, we compared the rate of accumulation of $\left[{ }^{3} \mathrm{H}\right]$ thymidine in uvrA and dnaA46 uvrA backgrounds shifted to $42^{\circ} \mathrm{C}$ after UV. Nonirradiated uvrA cells accumulated label at about the same rate as a wild-type strain (cf. Figs. $3 \mathrm{~A}$ and $5 \mathrm{~A})$. After UV, accumulation was reduced drastically and, at the same dose $\left(12 \mathrm{~J} / \mathrm{m}^{2}\right)$, to a level lower than in the dnaA46 strain (Fig. 5A; Supplementary Fig. $\mathrm{S} 3 \mathrm{~B})$. In the dnaA uvrA double mutant, the accumulation was even lower (Fig. 5A). This shows very clearly that the delay in progression of ongoing forks induced by UV cannot be calculated simply by looking at total $\left[{ }^{3} \mathrm{H}\right]$ thymidine incorporation (see also Appendix I in Materials and Methods).

\section{The origin to terminus ratio increases after UV irradiation}

The fluorescent images shown in Figure 2A demonstrate there is a substantial delay of ongoing replication. They indicate that the number of termini in UV-irradiated cells is still very low up to 90 min after the irradiation, but increases rapidly between 90 and $120 \mathrm{~min}$. However, this observation might also be explained if replication forks proceeded through to the terminus region without hindrance but segregation of the replicated termini was delayed. To address this possibility, we investigated the ratio of two chromosomal loci by Southern analysis. Two probes were used, one binding within mioC, which contains ori $C$, and one in ribA, which lies next to ter $A$. To facilitate the analysis, a $d n a C 7$ strain was used and synchronized by a shift to $42^{\circ} \mathrm{C}$ for $45 \mathrm{~min}$ prior to irradiation.

As expected, the nonirradiated control showed an increase in the origin signal relative to the terminus signal,
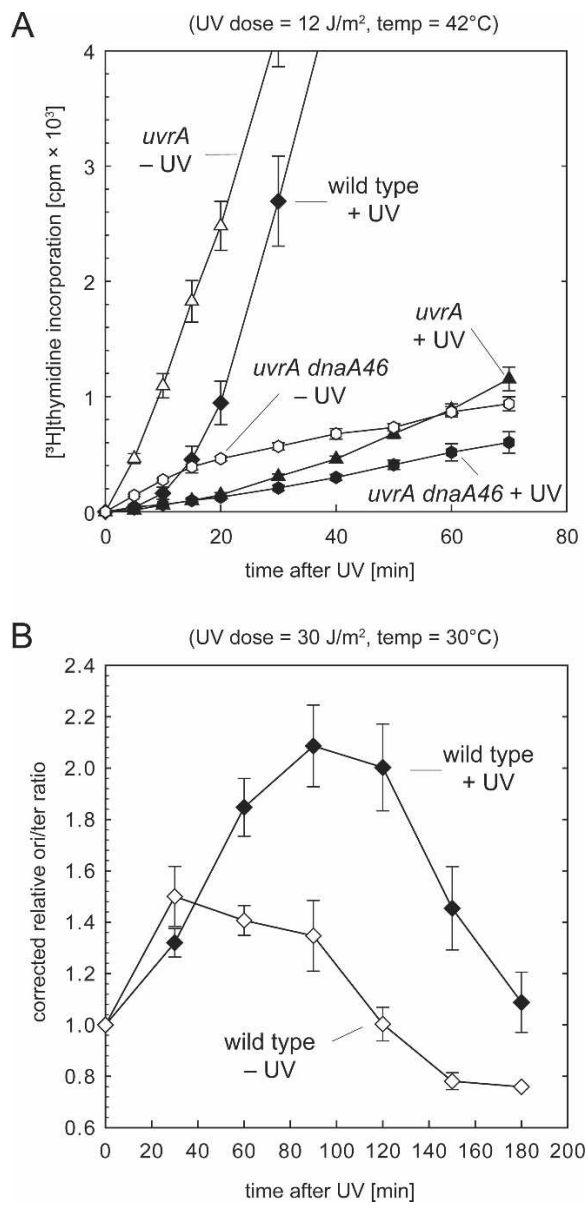

Figure 5. Effect of UV on DNA synthesis and chromosome replication. (A) $\left[{ }^{3} \mathrm{H}\right]$ thymidine incorporation in uvrA (AU1075) and uvrA dnaA46 (AU1072) cells. Data are the mean $\left({ }_{ \pm} \mathrm{SE}\right)$ of three experiments. Data for irradiated wild-type (N1141) cells (Fig. 3A) are included for comparison. (B) Changes in the origin to terminus ratio during incubation of irradiated and nonirradiated cells. The strain was RCe79 (dnaC7). Cells grown at $30^{\circ} \mathrm{C}$ were synchronized by incubation at $42^{\circ} \mathrm{C}$ for $45 \mathrm{~min}$ before irradiation and shifting back to $30^{\circ} \mathrm{C}$. Data are the mean $\left({ }_{ \pm} \mathrm{SE}\right)$ of three experiments.

reaching a ratio of 1.5 (Fig. $5 \mathrm{~B}$ ). The theoretical ratio should be $\sim 2$ for cells growing at $30^{\circ} \mathrm{C}$, but microscopic analysis revealed that the synchrony of the starting material was not complete (data not shown). The very first value, set to one, is therefore an underrepresentation of the real ratio. The ratio stayed roughly at 1.5 over $90 \mathrm{~min}$ and decreased after $3 \mathrm{~h}$ to $\sim 0.7$, which represents the cessation of replication as cells enter stationary phase. The value of $<1$ reflects the initial underestimation.

The origin/terminus ratio also increased after UV, but with a slight initial delay (Fig. 5B). However, unlike in the nonirradiated cells it continued to increase, indicating that the number of origins increases faster than the number of termini. After $120 \mathrm{~min}$, the ratio decreased. This pattern is in excellent agreement with the fluorescence microscopy data, showing that multiple termini foci appear between 90 and 120 min after irradiation. 
Therefore, it seems reasonable to conclude that ongoing replication is blocked and hence the terminus cannot be duplicated.

The BrdU incorporation experiments (Fig. 4) provide some additional insight into the extent of the delay. After a UV dose of $20 \mathrm{~J} / \mathrm{m}^{2}$ almost all of the bands that do not contain DNA fragments near oriC show at most a marginal increase in signal intensity for at least 15-20 min (Fig. 4B). Surprisingly, there seems to be quite rapid BrdU incorporation into all the fragments after this period. This does not require DnaA since the time course of BrdU incorporation looks very similar in a dnaA46 mutant at $42^{\circ} \mathrm{C}$ (Fig. 4C). However, synthesis depends almost completely on DnaC (Fig. 3A; Supplementary Fig. $\mathrm{S} 3 \mathrm{~A})$. So we can conclude there is a delay of at least 15-20 min before ongoing synthesis resumes.

\section{Replication resumes at a time when most UV-induced} lesions have been removed

What could be the reason for the apparent synchrony of replication restart revealed by BrdU incorporation, and the subsequent continuation of synthesis at a rate comparable to that in nonirradiated cells? One obvious process would be fork rescue coupled with removal of the UV-induced lesions. We therefore determined the rate of thymidine dimer removal in wild-type cells after a $30-\mathrm{J} / \mathrm{m}^{2}$ dose. This revealed that $\sim 80 \%$ of dimers are removed within $20 \mathrm{~min}$ (Fig. 4E), which is in good agreement with published data (Courcelle et al. 1999). Thus restart of stalled forks and damage removal may be closely coupled.

The data we have presented so far indicate that $\left[{ }^{3} \mathrm{H}\right]$ thymidine incorporation may be misleading in terms of the rate of ongoing replication because new initiation events at oriC and UV-induced synthesis contribute substantially to the total incorporation observed. Variation in the extent of origin firing may explain the reported differences in the amounts of DNA synthesis detected in UV-irradiated uvrA cells (Rupp and Howard-Flanders 1968; Courcelle et al. 2005, 2006).

If DNA synthesis in UV-irradiated uvrA cells were to have difficulty recovering, as suggested (Courcelle et al. 2005,2006 ), only those cells lacking any lesions between the fork and the terminus should complete replication. These should represent a minority of the total after UV doses introducing a substantial number of lesions. To address this possibility, we examined the origin to terminus ratio. Figure $6 \mathrm{~A}$ shows that after a dose of $5 \mathrm{~J} / \mathrm{m}^{2}$ an uvrA strain carrying origin and terminus arrays shows intense origin foci, as seen with the wild type at higher doses (Fig. 2A; Supplementary Fig. S1). However, the cells continued to filament throughout the 240-min post-irradiation incubation and there is no evidence of the regular dispersal of origin foci along these filaments or of their subsequent interspersion with replicated terminus foci (cf. Figs. 6A and 2B). Some filaments do ultimately show several foci for the terminus region, indicating that some replication of the terminus is possible, but this replication occurs much later than in wild-type cells (Fig. 6A; Supplementary Fig. S1).
The increase in the origin to terminus ratio was confirmed by Southern analysis. The ratio increased to $\sim 3.5$ by 120 min and then remained constant (Fig. 6B). That it does not reduce as in the wild type reinforces the idea that most uvrA cells have great difficulty replicating the terminus. This would be consistent with the fact that only $1.5 \%$ survive a UV dose of $5 \mathrm{~J} / \mathrm{m}^{2}$ (data not shown).

However, some multiplication of the terminus area is evident. To investigate whether this is due to generalized progression of replication forks or to some UV-induced replication initiated specifically near the terminus (Kogoma 1997), we examined the pattern of BrdU incorporation. Figure 6C shows substantial incorporation close to oriC, confirming that the origin continues to fire. There is also incorporation into more distally located fragments, including those at or near the terminus. The PFGE resolved several such fragments (identified with a bracket in Fig. 6C). However, their labeling is much delayed-much more so than is seen in wild-type cells despite the fourfold lower UV dose (note the different time scales in Figs. 4B, 6C). Thus, even without excision repair, some replication is able to resume to complete chromosome duplication, though this is much delayed. This fits with the observation that $37 \%$ of uvrA cells survive a UV dose introducing $~ 50$ dimers per chromosome (Rupp and Howard-Flanders 1968), or only 3040 dimers per chromosome according to the number of lesions generated per joule estimated by Sedgwick (1975) and Courcelle et al. (2006).

What happens in uvrA cells if the lesion density is high? Figure $6 \mathrm{~B}$ shows that the origin to terminus ratio increased far more slowly when the UV dose was increased from $5 \mathrm{~J} / \mathrm{m}^{2}$ to $30 \mathrm{~J} / \mathrm{m}^{2}$, and never decreased, indicating that there is much less origin firing or that the duplicated DNA is degraded. We assume this reflects the higher incidence of damage at or close to oriC, which does not allow forks coming from the origin to progress very far and thus limits the ability of the origin to fire. A high lesion density in combination with a lack of repair therefore might directly influence the capability of origin firing. Consistent with this, the uvrA array strain showed a low number of both origin and terminus foci even after 180 min post-UV (Supplementary Fig. S2). After prolonged incubation the filaments seem to accumulate dispersed aggregations of the fluorescent repressors rather than foci.

Taken together, the data we have presented indicate that the substantial DNA synthesis associated with origin firing seen in wild-type cells depends on nucleotide excision repair. This is consistent with the results described by Courcelle et al. $(2005,2006)$. Our results emphasize the importance of eliminating origin firing and UV-induced synthesis when evaluating the progression of pre-existing replication forks in UV-irradiated cells.

\section{Discussion}

We revisited the question of what happens to replication forks when they encounter UV lesions in the template DNA. The data presented demonstrate that replication 
Rudolph et al.

\section{A (UV dose $\left.=5 \mathrm{~J} / \mathrm{m}^{2}\right)$}
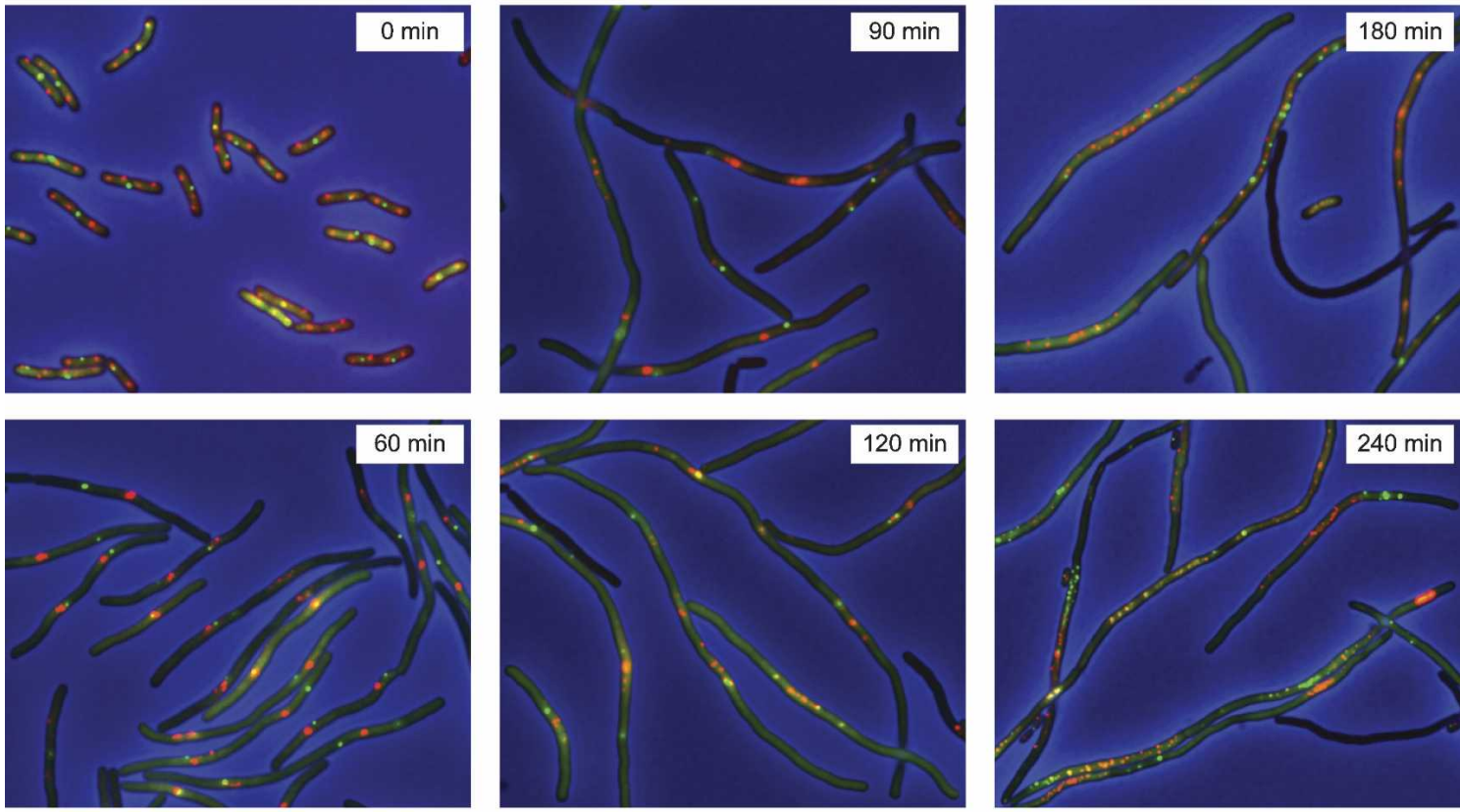

B

C

(UV dose $=5 \& 30 \mathrm{~J} / \mathrm{m}^{2}$, temp $\left.=30^{\circ} \mathrm{C}\right)$
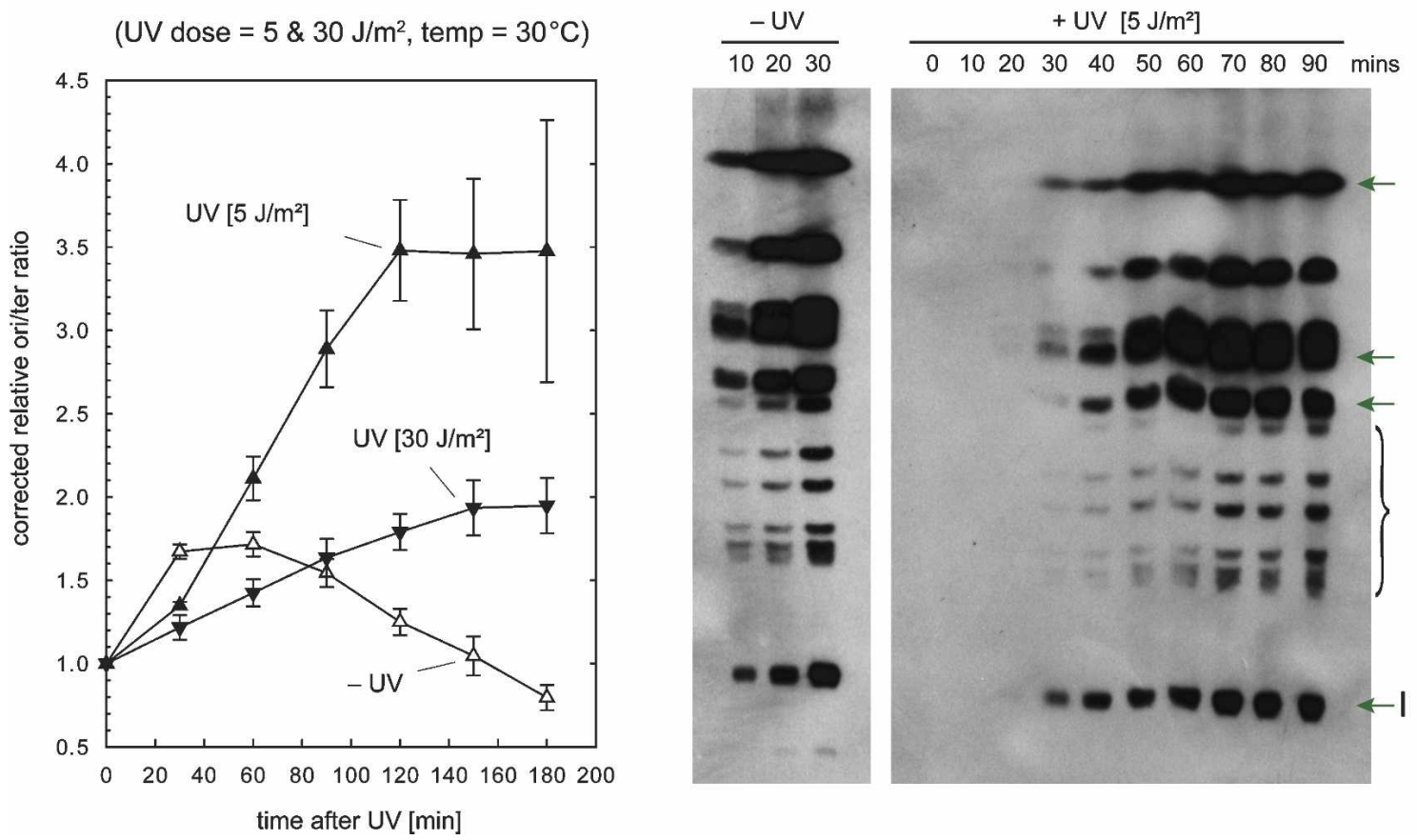

Figure 6. Effect of UV lesions on cell cycle progression and DNA synthesis in the absence of DNA excision repair. $(A)$ Fluorescence microscopy showing replication of origin (red foci) and terminus (green foci) areas of the chromosome. The strain was RCe129 (uvrA). (B) Changes in the origin to terminus ratio during incubation of irradiated and nonirradiated cells. The strain was RCe120 (dnaC7 uvrA). Cells grown at $30^{\circ} \mathrm{C}$ were synchronized by incubation at $42^{\circ} \mathrm{C}$ for 45 min before irradiation and shifting back to $30^{\circ} \mathrm{C}$. Data are the mean $( \pm S E)$ of three or more experiments. $(C)$ Fluorograph showing the time course and pattern of BrdU incorporation into the chromosome of uvrA strain N4280 with or without UV irradiation as indicated.

stops for a minimum of 15-20 min, or at least slows down dramatically, before resuming at the original rate. The data also show that undamaged origins continue to fire and that UV also induces synthesis that is independent of the initiator protein, DnaA. Our observation that replication restart occurs when most lesions have been 
removed raises the possibility that replication restart and lesion removal are coupled. Replication and cell division suffer tremendous delays if lesion removal is prevented. Finally, we demonstrate that essentially all the synthesis seen after irradiation depends on DnaC, which is required to load the DnaB replicative helicase.

These data fit well with models invoking the stalling of forks at UV lesions and their extensive processing before replication can restart (Fig. 1A, ii). These models have been reviewed recently (McGlynn and Lloyd 2002). Essentially, these models propose that a replication fork may skip over a lesion in the lagging strand template, leaving a gap to be filled by recombination. But when it encounters a polymerase-blocking lesion in the leading strand template, the two polymerases are decoupled. Fork progression coupled with continued extension of the lagging strand exposes the leading strand template (Higuchi et al. 2003; Pages and Fuchs 2003; McInerney and O'Donnell 2004). RecA loads on this exposed strand, forming a nucleoprotein filament that acts both to induce the SOS repair response and to provide means to process and rescue the damaged fork. After a delay associated with restoration of the fork, replication resumes when either PriA or PriC loads DnaB to enable assembly of a new replisome (Fig. 1A, ii).

In the meantime, SOS induction will have led to an early and rapid increase in the proteins (UvrA and UvrB) needed to initiate nucleotide excision repair, enabling most of the lesions in the chromosome to be removed rapidly. Therefore, by the time replication is able to restart, it will be able to continue with a minimum of further impediment. Our results demonstrate that replication resumes at all sites in the chromosome at a rate commensurate with that in nonirradiated cells (Fig. 4B), consistent with this model.

Without means to remove lesions, uvrA cells would face difficulties consistent with their extreme UV sensitivity. The much-delayed DNA synthesis in these cells (Figs. 5A, 6; Rupp and Howard-Flanders 1968; Courcelle et al. 2005, 2006) is consistent with replication forks stuttering at lesion after lesion, and with a need to reassemble a replisome each time. The cells that survive at low doses presumably do so through a combination of template switching, gap filling by recombination, and possibly translesion synthesis, aided perhaps by the SOSinduced elevation of the associated activities.

This view of events in UV-irradiated cells stands in sharp contrast to the idea that forks proceed largely unhindered, skipping over lesion after lesion and leaving many gaps in their wake to be filled by recombination (Fig. 1A, i), as illustrated originally by Rupp and HowardFlanders (1968). Our studies revealed that $\left[{ }^{3} \mathrm{H}\right]$ thymidine is incorporated into the DNA of UV-irradiated uvrA cells with a delay close to the estimate made by Rupp and Howard-Flanders (1968) (see Appendix I in Materials and Methods). However, the evidence of origin firing and UV-induced synthesis revealed by our studies demonstrates clearly that averaging the delay over the number of lesions is very misleading. Pages and Fuchs (2003) observed a delay in replicating past a single leading strand block corresponding to about one cell cycle. Our estimates of the delay caused by UV are in accord with this observation.

Many inferences have been drawn from the inverse relationship between the length of newly synthesized DNA and the UV dose, and the fact that the molecular weight of the new DNA strands increased during postirradiation incubation (Rupp and Howard-Flanders 1968; Bridges and Sedgwick 1974). However, new strands extended by refiring of the origin or by UV-induced initiation at other sites would have these same two properties. Our studies suggest such strands might comprise a substantial fraction of the newly synthesized DNA.

Our results do not eliminate the idea that a fork may skip lesions, even some on the leading strand (Heller and Marians 2006), leaving gaps to be filled by recombination. Iyer and Rupp (1971) demonstrated there are gaps in DNA made during growth of a UV-irradiated uvrA strain but did not determine whether these were present in both nascent strands. At least one gap is likely when the first lesion encountered is in the lagging strand template. However, the delay resulting from subsequent fork stalling at a lesion in the leading strand, coupled with the rapid removal of lesions during this period, makes it likely wild-type cells would have to deal with few gaps on the whole. Our assays are not sufficiently sensitive to estimate how many on average.

The observed delay before replication can resume suggests extensive processing of stalled forks, but why this should take at least $15 \mathrm{~min}$, and possibly much longer, is not clear. A possible clue comes from the need for DnaB loading. It may simply take time to assemble new replisomes. Dissociation of stalled replisomes may inactivate one or more key components, or these components may be in limited supply as a part of normal cell cycle regulation. Increased demand for these proteins may also result from the continuing oriC firing and UV-induced initiations. Furthermore, the processing of stalled forks might be slow. It has been suggested that RecA might be involved in the stabilization and/or reversal of stalled replication forks (Courcelle and Hanawalt 2003), and it has been shown that the strand exchange reaction promoted by RecA in vitro is relatively slow (CameriniOtero and Hsieh 1993; Voloshin and Camerini-Otero 2004). Stabilization or processing of stalled forks by RecA could therefore take considerable time. Even if replisomes are reassembled or processed quickly, it is possible cells deliberately slow down replication restart (Opperman et al. 1999; McInerney and O'Donnell 2004).

Delaying replication restart while allowing origin firing may be of selective advantage in a rapidly dividing cell population exposed to DNA damage. It would facilitate safe removal of any lesions and enable a cluster of replication forks to create multiple copies of the genome once the lesions are removed, and subsequently the equivalent number of viable cells. This would compensate somewhat for any delay caused initially by the blocking lesion.

By providing time to clear the path for replication to resume, the delay in replication restart also eliminates a 
second objection to the Rupp and Howard-Flanders model. Wild-type E. coli cells withstand UV doses that introduce a thousand or more pyrimidine dimers into the chromosome with little reduction in survival and only a modest increase in mutation. If replication forks skip past many of these lesions, as in the Rupp and HowardFlanders model, an inordinate number of recombination events might be required to close all the gaps left behind, even if some lesions were removed by excision repair. High levels of recombination are known to be destabilizing for the genome because they can elicit illegitimate exchanges and also because the intermediates delay chromosome segregation and cell septation. This is evident from the high mutation rates and general debility of "hyper-rec" mutants, such as those lacking UvrD helicase (Arthur and Lloyd 1980; Lloyd 1983; Bierne et al. 1997). Mutations that elevate mitotic recombination in eukaryotes have a similar destabilizing effect and those in humans are noted for their association with a muchelevated risk of cancer (Myung et al. 2001). Most eukaryotes appear to curb the activity of the Rad51 family of recombinases (Krejci et al. 2003; Veaute et al. 2003), except when efficient recombination is needed, as in meio- sis (Nicolas et al. 1989). E. coli has also evolved mechanisms to curb RecA during normal growth (Flores et al. 2005; Mahdi et al. 2006). Thus, the delay in restarting replication revealed in our work may be yet another reflection of how advantageous it is to avoid recombination whenever possible.

\section{Materials and methods}

\section{Bacterial strains}

The studies described used derivatives of wild-type E. coli K-12 MG1655 (Table 1), with the exception of the $\left[{ }^{3} \mathrm{H}\right]$ thymidine incorporation assays when we employed strain N1141 and its derivatives. N1141 carries thy A54 along with a deo mutation, allowing growth with low levels of thymine. For fluorescence microscopy, MG1655 derivatives carrying lacO240 and tet $\mathrm{O} 240$ arrays were transformed with pLAU53, which encodes arabinose-inducible LacI-eCFP and TetR-eYFP (Lau et al. 2003).

\section{Media and general methods}

LB broth and 56/2 salts media, and methods for monitoring cell growth and P1vir transduction and determining sensitivity to UV have been cited (McGlynn and Lloyd 2000).

Table 1. E. coli K-12 strains

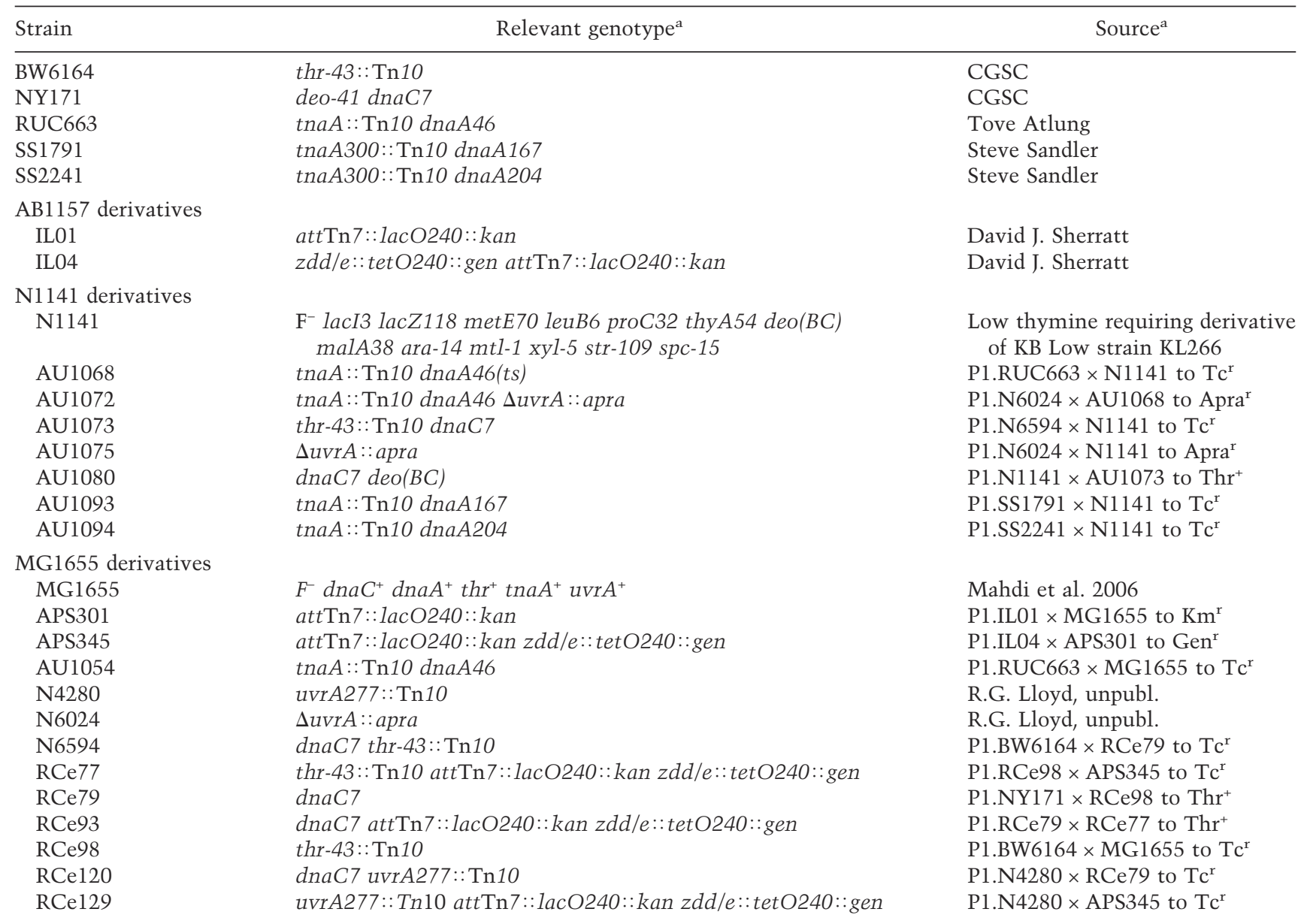

${ }^{\mathrm{a}}$ The abbreviations kan, apra, and gen refer to insertions conferring resistance to kanamycin $\left(\mathrm{Km}^{\mathrm{r}}\right)$, apramycin $\left(\right.$ Apra $\left.{ }^{\mathrm{r}}\right)$, and gentamycin $\left(\mathrm{Gen}^{\mathrm{r}}\right)$, respectively. Tn10 confers resistance to tetracycline $\left(\mathrm{Tc}^{\mathrm{r}}\right)$. Strains carrying dnaA46, dnaA167, dnaA204, or dnaC7 are temperature sensitive for growth. (CGSC) Coli Genetic Stock Center, Yale University. 


\section{Fluorescence microscopy}

Cells were grown to an $A_{650}$ of 0.2 in LB broth supplemented with $0.5 \mathrm{mM}$ IPTG and $40 \mathrm{ng} / \mathrm{mL}$ anhydrotetracycline to reduce repressor binding, without compromising focus formation. A 1-mL sample was removed and expression was induced at high levels by adding arabinose to $0.2 \%$. The rest of the cells were pelleted, UV-irradiated on the surface of LB agar, and resuspended in the original, but filter-sterilized, supernatant to continue incubation before inducing further $1-\mathrm{mL}$ samples at intervals thereafter. Arabinose-induced cells were transferred to a thin $1 \%$ LB agarose layer on microscopic slides, visualized with a BX-52 Olympus microscope equipped with a coolSNAP ${ }^{\mathrm{TM}} \mathrm{HQ}$ camera (Photometrics). eCFP and eYFP foci were visualized using the JP4-CFP-YFP filterset 86002v2 (Chroma). Images were taken and analyzed by MetaMorph 6.2 (Universal Imaging) and processed using MetaMorph and Adobe Photoshop.

\section{Multiplication of cells surviving UV irradiation}

To monitor recovery of cells surviving UV irradiation, cultures of the strains indicated were grown in LB broth and the cells were irradiated with UV as for fluorescence microscopy. The cells were resuspended in the original, but filter-sterilized, supernatant and diluted 10,000-fold in conditioned medium, which was created by growing the wild-type strain in fresh LB broth to an $A_{650}$ of 0.2 with subsequent sterile filtration. The diluted cells were incubated in a $37^{\circ} \mathrm{C}$ shaking water bath and at each time point samples were removed, mixed with $2.5 \mathrm{~mL}$ of molten $0.6 \%$ top agar kept at $42^{\circ} \mathrm{C}$, and plated on LB agar. At later time points, the samples were diluted a further 10- or 100 -fold in conditioned medium before plating. Colonies were counted after incubation for $18-24 \mathrm{~h}$ at $37^{\circ} \mathrm{C}$.

\section{Measurement of DNA synthesis}

Cultures were grown with vigorous shaking at $30^{\circ} \mathrm{C}$ in Davis medium $\left[0.7 \% \mathrm{~K}_{2} \mathrm{HPO}_{4}, 0.3 \% \mathrm{KH}_{2} \mathrm{PO}_{4}, 0.1 \%\left(\mathrm{NH}_{4}\right)_{2} \mathrm{SO}_{4}, 0.05 \%\right.$ $\mathrm{Na}_{3} \mathrm{C}_{6} \mathrm{H}_{5} \mathrm{O}_{7} \cdot \mathrm{H}_{2} \mathrm{O}, 0.0001 \%$ thiamine, $0.4 \%$ glucose, $0.01 \%$ $\mathrm{MgSO}_{4}$ ] supplemented with $1 \%$ casamino acids and $5 \mu \mathrm{g} / \mathrm{mL}$ thymidine. At an $A_{650}$ of 0.2 , the cells were filtered onto 0.22 $\mu \mathrm{m}$ cellulose acetate (Corning) and irradiated directly on the filter, or mock-irradiated, before resuspending in the filtrate. $\left[{ }^{3} \mathrm{H}\right]$ thymidine (specific activity $80.0 \mathrm{Ci} / \mathrm{mmol}$, Amersham) was added to $2 \mu \mathrm{Ci} / \mathrm{mL}$ before continuing incubation as indicated. Twenty-microliter samples were taken at intervals, applied to $2.5-\mathrm{cm}^{2}$ filters (Whatman $3 \mathrm{MM}$ ), and immediately immersed in ice-cold 5\% trichloroacetic acid for a minimum of $30 \mathrm{~min}$. Filters were washed in three changes of fresh trichloroacetic acid and two of ethanol and dried, and the bound radioactivity was counted by liquid scintillation.

\section{BrdU labeling}

Cells were grown in 56/2 salts supplemented with $0.2 \%$ casamino acids and $0.32 \%$ glucose to an $A_{650}$ of 0.2 and UVirradiated as for fluorescence microscopy. Cells were resuspened in the sterile filtered supernatant and the first 2-mL sample was removed. BrdU (Sigma) was added to the rest of the culture to $20 \mu \mathrm{g} / \mathrm{mL}$. Two-milliliter samples were taken every 5 min, pelleted, and resuspended in $85 \mu \mathrm{L}$ TEE buffer $(10 \mathrm{mM}$ Tris. $\mathrm{HCl}, 10 \mathrm{mM}$ EGTA, $100 \mathrm{mM}$ EDTA at $\mathrm{pH}$ 8.0), containing $0.05 \%$ lauroylsarcosine. Eighty-five microliters of liquid $1 \%$ agarose in TEE buffer were added and the mixture was solidified in a disposable plug former (Bio-Rad) at $4^{\circ} \mathrm{C}$. Plugs were treated with $5 \mathrm{mg} / \mathrm{mL}$ lysozyme in $3 \mathrm{~mL}$ of TEE buffer containing
$0.05 \%$ lauroylsarcosine for $2 \mathrm{~h}$ at $37^{\circ} \mathrm{C}$ and then overnight at $52^{\circ} \mathrm{C}$ with $5 \mathrm{mg} / \mathrm{mL}$ proteinase $\mathrm{K}$ in $3 \mathrm{~mL}$ of TEE containing $1 \%$ SDS. Plugs were washed in TEE for $30 \mathrm{~min}$ at $37^{\circ} \mathrm{C}$, treated with $1 \mathrm{mM}$ phenylmethane sulphonyl fluoride in fresh TEE for $1 \mathrm{~h}$ at $37^{\circ} \mathrm{C}$, and washed twice in fresh TEE for $30 \mathrm{~min}$ at $37^{\circ} \mathrm{C}$. The plugs were subsequently transferred into $300 \mu \mathrm{L}$ of restriction enzyme buffer and incubated for $30 \mathrm{~min}$ at room temperature, the buffer was changed, and $25 \mathrm{U}$ of NotI (New England Biolabs) was added. Chromosomal DNA was digested overnight and the fragments were separated on a $0.8 \%$ agarose gel in $0.5 \times$ TBE using a CHEF Mapper PFGE system (Bio-Rad) running with a gradient voltage of $6 \mathrm{~V} / \mathrm{cm}$, an included angle of $120^{\circ}$, and initial and final switch times of 1.65 and $32.45 \mathrm{sec}$, respectively, with a run time of $20 \mathrm{~h}$ at $14^{\circ} \mathrm{C}$. For resolution of band I in Figure $4 \mathrm{~B}$ the running conditions were the same, except the initial and final switch times were 1.65 and $2.43 \mathrm{sec}$, respectively. DNA was transferred to a Hybond- $\mathrm{N}^{+}$Membrane (Amersham) by alkaline vacuum transfer and UV-cross-linked (120 $\left.\mathrm{mJ} / \mathrm{cm}^{2}\right)$. After blocking with TBS $(50 \mathrm{mM}$ Tris. $\mathrm{HCl}, 150 \mathrm{mM}$ $\mathrm{NaCl}$ at $\mathrm{pH} 8.0$ ) containing $1 \%$ milk powder, the membrane was incubated for $2 \mathrm{~h}$ in the presence of mouse anti-BrdU antibody (Santa Cruz Biotechnology), diluted 1:5000 in TBS. Horse radish peroxidase-conjugated secondary antibody (goat anti-mouse, Bio-Rad) was used at a dilution of 1:10,000 for $1 \mathrm{~h}$. The membrane was incubated with ECL Plus Western Blotting Detection Reagents (GE Healthcare) and the signal was visualized by exposure to X-Omat UV Plus film (Kodak).

\section{Southern analysis of the origin to terminus ratio}

Cultures of $d n a C 7$ strains were grown at $30^{\circ} \mathrm{C}$ in LB broth to an $A_{650}$ of 0.2 and shifted for $45 \mathrm{~min}$ to $42^{\circ} \mathrm{C}$ for synchronization. Irradiation was as for fluorescence microscopy before continuing incubation at $30^{\circ} \mathrm{C}$. Four-milliliter samples were removed at each time point. Cells were pelleted, resuspended in $500 \mu \mathrm{L} 10$ $\mathrm{mM}$ Tris $(\mathrm{pH} 8.0), 10 \mathrm{mM} \mathrm{NaCl}$, and $10 \mathrm{mM}$ EDTA before adding $30 \mu \mathrm{g}$ RNaseA, $50 \mu \mathrm{L}$ Triton X-100 (10\%), and $250 \mu \mathrm{g}$ of lysozyme, and incubated for $30 \mathrm{~min}$ at $37^{\circ} \mathrm{C}$. Three-hundred micrograms of proteinase $\mathrm{K}$ were added and the sample was shifted to $65^{\circ} \mathrm{C}$ for $120 \mathrm{~min}$. The DNA was extracted twice with phenol-chloroform and precipitated in $2.5 \mathrm{M}$ ammonium acetate and 2 vol of ethanol. Purified DNA was resuspended in TE buffer. Three micrograms of chromosomal DNA of each sample were digested with XmaI and HpaI, and the fragments were resolved on a $0.7 \%$ agarose gel $(45 \mathrm{~V}, 1 \times \mathrm{TAE}, 16 \mathrm{~h})$, transferred to a Zeta-Probe GT Membrane by alkaline vacuum transfer, and UV-cross-linked $\left(120 \mathrm{~mJ} / \mathrm{cm}^{2}\right)$. One-hundred nanograms of each ${ }^{32} \mathrm{P}$-labeled probe were annealed overnight at $65^{\circ} \mathrm{C}$ in $7 \times$ SSPE (150 mM NaCl, $10 \mathrm{mM} \mathrm{NaH} \mathrm{PO}_{4} \cdot \mathrm{H}_{2} \mathrm{O}, 1 \mathrm{mM}$ EDTA at $\mathrm{pH}$ 7.4), containing $60 \mathrm{mg} / \mathrm{mL}$ dextran sulphate and $1.2 \%$ SDS. Signal was visualized using a Kodak Storage Phosphor Screen, scanned with a STORM scanner system (Molecular Dynamics), and quantified with ImageQuant 5.2 (Molecular Dynamics). For calculation of the corrected relative origin to terminus ratio, the signal intensity of the origin signal was divided by the intensity of the terminus signal and all the ratios divided by the ratio of the very first sample directly after synchronization. Values are the mean of three experiments.

\section{Thymine dimer removal}

Cells were grown in LB broth and UV-irradiated as for fluorescence microscopy. Two-milliliter samples were removed, and DNA was extracted as for the Southern analyses and adjusted with TE to $250 \mu \mathrm{g} / \mathrm{mL}$. Following denaturation by boiling, 500ng samples were transferred to a Zeta-Probe GT Membrane via 
dot blot. DNA was baked on the membrane for $2 \mathrm{~h}$ at $80^{\circ} \mathrm{C}$, probed with mouse anti-CPD antibody (Sigma), and diluted 1:1000, and complexes were detected with sheep anti-mouse, alkaline phosphatase-conjugated secondary antibody (Sigma), diluted 1:10,000 as described for detection of BrdU. Signal was developed using an AttoPhos AP Fluorescent Substrate System (Promega), measured using a STORM scanner system (Molecular Dynamics) in fluorescence mode (450-nm excitation, 520-nm emission), and quantified with ImageQuant 5.2.

Appendix I. Calculations of DNA synthesis delay in UV-irradiated cells and additional discussion

Calculations are based on the following assumptions:

(1) Cells growing in minimal salts medium have two forks per cell on average.

(2) Each fork takes $\sim 40 \mathrm{~min}$ to traverse from oriC to ter.

(3) Therefore, with a genome of $\sim 4600 \mathrm{~kb}$, replication proceeds in nonirradiated cells at a rate of $\sim 2 \mathrm{~kb} / \mathrm{sec}$, or $\sim 120 \mathrm{~kb} / \mathrm{min}$.

(4) A dose of $1 \mathrm{~J} / \mathrm{m}^{2} \mathrm{UV}$ introduced $\sim 40$ dimers per chromosome (Courcelle et al. 2006), which equates to one dimer every 115 $\mathrm{kb}$. Therefore, a dose of $12 \mathrm{~J} / \mathrm{m}^{2}$ introduces a lesion every 9 $\mathrm{kb}$ or so, while a dose of $5 \mathrm{~J} / \mathrm{m}^{2}$ introduces a lesion about every $21 \mathrm{~kb}$.

From the data in Figures 3A and 5A and Supplementary Figure S3B, which measured $\left[{ }^{3} \mathrm{H}\right]$ thymidine incorporation after a UV dose of $12 \mathrm{~J} / \mathrm{m}^{2}$ (or $5 \mathrm{~J} / \mathrm{m}^{2}$ ) (Supplementary Fig. S3B), we estimated approximately how long it took for irradiated wild-type, uvrA, and uvrA dnaA46 cells to incorporate the same amount of label as nonirradiated wild-type cells. The calculations were based on the value for uvrA dnaA46 at $70 \mathrm{~min}$ and gave the following estimates for the delay in incorporation of the label in the UV-irradiated cells:

(1) Nonirradiated wild type $=8 \mathrm{~min}$.

(2) Irradiated wild type $=16 \mathrm{~min}$, a delay of $8 \mathrm{~min}$.

(3) Irradiated $u v r A=43 \mathrm{~min}$, a delay of $35 \mathrm{~min}$.

(4) Irradiated uvrA dnaA46 = $70 \mathrm{~min}$, a delay of $62 \mathrm{~min}$.

(5) Irradiated $\operatorname{uvr} A\left(5 \mathrm{~J} / \mathrm{m}^{2}\right)=23 \mathrm{~min}$, a delay of $15 \mathrm{~min}$.

In $8 \mathrm{~min}$, the nonirradiated wild type should replicate $\sim 960 \mathrm{~kb}$ of DNA (480 kb per fork). In the irradiated cells, replication forks would encounter $\sim 107$ pyrimidine dimers after $12 \mathrm{~J} / \mathrm{m}^{2}$, or 45 dimers after $5 \mathrm{~J} / \mathrm{m}^{2}$, if they replicated the same length of DNA. From the delay in $\left[{ }^{3} \mathrm{H}\right]$ thymidine incorporation, we can estimate the average delay per dimer (to the nearest second):

(1) Wild type $=5 \mathrm{sec}$.

(2) $u v r A=20 \mathrm{sec}$.

(3) uvrA dnaA46 $=35 \mathrm{sec}$.

(4) $\operatorname{uvrA}\left(5 \mathrm{~J} / \mathrm{m}^{2}\right)=19 \mathrm{sec}$.

These calculations demonstrate that (1) UV lesions delay fork progression; (2) by removing lesions, the excision repair system promotes fork progression; and (3) a significant amount of the DNA synthesis detected after UV irradiation is due to origin firing. Given there is also substantial UV-induced, DnaA-independent synthesis, these calculations reinforce the dangers of averaging the delay over the number of lesions and of ignoring the initiation of new synthesis. Not taking these factors into account can lead to the conclusion that forks skip over lesions without much delay.

The absolute delay of $35 \mathrm{~min}$ seen in the uvrA strain, or 62 min if origin firing is blocked, is in line with the prolonged delay in replication past a leading strand lesion observed by Pages and Fuchs (2003). The delayed BrdU incorporation and delayed replication of the terminus region we observed in a UV-irradiated uvrA strain can be explained, therefore, if replication stops or slows down dramatically very soon after encountering a lesion in the leading strand template. However, since these cells have multiple lesions, we cannot exclude the possibility that forks skip over a few such lesions, as suggested (Heller and Marians 2006).

\section{Acknowledgments}

We thank those who kindly sent strains, Tim Moore and Andrew Savory for help with the microscopy, and Carol Buckman, Lynda Harris, and Lee Shunburne for excellent technical help. This work was funded by the Medical Research Council.

\section{References}

Arthur, H.M. and Lloyd, R.G. 1980. Hyper-recombination in uvrD mutants of Escherichia coli K-12. Mol. Gen. Genet. 180: $185-191$.

Bierne, H., Seigneur, M., Ehrlich, S.D., and Michel, B. 1997. uvrD mutations enhance tandem repeat deletion in the Escherichia coli chromosome via SOS induction of the RecF recombination pathway. Mol. Microbiol. 26: 557-567.

Billen, D. 1969. Replication of the bacterial chromosome: Location of new initiation sites after irradiation. J. Bacteriol. 97: 1169-1175.

Bridges, B.A. and Sedgwick, S.G. 1974. Effect of photoreactivation on the filling of gaps in deoxyribonucleic acid synthesized after exposure of Escherichia coli to ultraviolet light. J. Bacteriol. 117: 1077-1081.

Camerini-Otero, R.D. and Hsieh, P. 1993. Parallel DNA triplexes, homologous recombination, and other homologydependent DNA interactions. Cell 73: 217-223.

Courcelle, J. and Hanawalt, P.C. 2003. RecA-dependent recovery of arrested DNA replication forks. Annu. Rev. Genet. 37: 611-646.

Courcelle, J., Crowley, D.J., and Hanawalt, P.C. 1999. Recovery of DNA replication in UV-irradiated Escherichia coli requires both excision repair and recF protein function. J. Bacteriol. 181: 916-922.

Courcelle, J., Donaldson, J.R., Chow, K.H., and Courcelle, C.T. 2003. DNA damage-induced replication fork regression and processing in Escherichia coli. Science 299: 1064-1067.

Courcelle, C.T., Belle, J.J., and Courcelle, J. 2005. Nucleotide excision repair or polymerase V-mediated lesion bypass can act to restore UV-arrested replication forks in Escherichia coli. J. Bacteriol. 187: 6953-6961.

Courcelle, C.T., Chow, K.H., Casey, A., and Courcelle, J. 2006. Nascent DNA processing by RecJ favors lesion repair over translesion synthesis at arrested replication forks in Escherichia coli. Proc. Nat1. Acad. Sci. 103: 9154-9159.

Flores, M.J., Sanchez, N., and Michel, B. 2005. A fork-clearing role for UvrD. Mol. Microbiol. 57: 1664-1675.

Fujiwara, Y. and Tatsumi, M. 1976. Replicative bypass repair of ultraviolet damage to DNA of mammalian cells: Caffeine sensitive and caffeine resistant mechanisms. Mutat. Res. 37: 91-110.

Heller, R.C. and Marians, K.J. 2006. Replication fork reactivation downstream of a blocked nascent leading strand. Nature 439: $557-562$.

Higgins, N.P., Kato, K., and Strauss, B. 1976. A model for rep- 
lication repair in mammalian cells. J. Mol. Biol. 101: 417425.

Higuchi, K., Katayama, T., Iwai, S., Hidaka, M., Horiuchi, T., and Maki, H. 2003. Fate of DNA replication fork encountering a single DNA lesion during oriC plasmid DNA replication in vitro. Genes Cells 8: 437-449.

Iyer, V.N. and Rupp, W.D. 1971. Usefulness of benzoylated naphthoylated DEAE-cellulose to distinguish and fractionate double-stranded DNA bearing different extents of single-stranded regions. Biochim. Biophys. Acta 228: 117126.

Jonczyk, P. and Ciesla, Z. 1979. DNA synthesis in UV-irradiated Escherichia coli K-12 strains carrying dnaA mutations. Mol. Gen. Genet. 171: 53-58.

Khidhir, M.A., Casaregola, S., and Holland, I.B. 1985. Mechanism of transient inhibition of DNA synthesis in ultravioletirradiated E. coli: Inhibition is independent of recA whilst recovery requires RecA protein itself and an additional, inducible SOS function. Mol. Gen. Genet. 199: 133-140.

Kogoma, T. 1997. Stable DNA replication: Interplay between DNA replication, homologous recombination, and transcription. Microbiol. Mol. Biol. Rev. 61: 212-238.

Krejci, L., Van Komen, S., Li, Y., Villemain, J., Reddy, M.S., Klein, H., Ellenberger, T., and Sung, P. 2003. DNA helicase Srs2 disrupts the Rad51 presynaptic filament. Nature 423: 305-309.

Lau, I.F., Filipe, S.R., Soballe, B., Okstad, O.A., Barre, F.X., and Sherratt, D.J. 2003. Spatial and temporal organization of replicating Escherichia coli chromosomes. Mol. Microbiol. 49: 731-743.

Lloyd, R.G. 1983. lexA dependent recombination in uvrD strains of Escherichia coli. Mol. Gen. Genet. 189: 157-161.

Mahdi, A.A., Buckman, C., Harris, L., and Lloyd, R.G. 2006. Rep and PriA helicase activities prevent RecA from provoking unnecessary recombination during replication fork repair. Genes \& Dev. 20: 2135-2147.

Marians, K.J. 1992. Prokaryotic DNA replication. Annu. Rev. Biochem. 61: 673-719.

Marians, K.J. 2004. Mechanisms of replication fork restart in Escherichia coli. Philos. Trans. R. Soc. Lond. B Biol. Sci. 359: 71-77.

McGlynn, P. and Lloyd, R.G. 2000. Modulation of RNA polymerase by (p)ppGpp reveals a RecG-dependent mechanism for replication fork progression. Cell 101: 35-45.

McGlynn, P. and Lloyd, R.G. 2002. Recombinational repair and restart of damaged replication forks. Nat. Rev. Mol. Cell Biol. 3: 859-870.

McInerney, P. and O'Donnell, M. 2004. Functional uncoupling of twin polymerases: Mechanism of polymerase dissociation from a lagging-strand block. I. Biol. Chem. 279: 2154321551.

Meneghini, R. and Hanawalt, P.C. 1975. Postreplication repair in human cells: On the presence of gaps opposite dimers and recombination. Basic Life Sci. 5B: 639-642.

Michel, B., Grompone, G., Flores, M.J., and Bidnenko, V. 2004. Multiple pathways process stalled replication forks. Proc. Natl. Acad. Sci. 101: 12783-12788.

Myung, K., Chen, C., and Kolodner, R.D. 2001. Multiple pathways cooperate in the suppression of genome instability in Saccharomyces cerevisiae. Nature 411: 1073-1076.

Nicolas, A., Treco, D., Schultes, N.P., and Szostak, J.W. 1989. An initiation site for meiotic gene conversion in the yeast Saccharomyces cerevisiae. Nature 338: 35-39.

Opperman, T., Murli, S., Smith, B.T., and Walker, G.C. 1999. A model for a umuDC-dependent prokaryotic DNA damage checkpoint. Proc. Natl. Acad. Sci. 96: 9218-9223.
Pages, V. and Fuchs, R.P. 2003. Uncoupling of leading- and lagging-strand DNA replication during lesion bypass in vivo. Science 300: 1300-1303.

Rupp, W.D. and Howard-Flanders, P. 1968. Discontinuities in the DNA synthesized in an excision-defective strain of Escherichia coli following ultraviolet irradiation. J. Mol. Biol. 31: 291-304.

Sedgwick, S.G. 1975. Genetic and kinetic evidence for different types of postreplication repair in Escherichia coli B. J. Bacteriol. 123: 154-161.

Sherratt, D.J. 2003. Bacterial chromosome dynamics. Science 301: 780-785.

Veaute, X., Jeusset, J., Soustelle, C., Kowalczykowski, S.C., Le Cam, E., and Fabre, F. 2003. The Srs2 helicase prevents recombination by disrupting Rad51 nucleoprotein filaments. Nature 423: 309-312.

Voloshin, O.N. and Camerini-Otero, R.D. 2004. Synaptic complex revisited; a homologous recombinase flips and switches bases. Mol. Cell 15: 846-847.

Wang, X., Possoz, C., and Sherratt, D.J. 2005. Dancing around the divisome: Asymmetric chromosome segregation in Escherichia coli. Genes \& Dev. 19: 2367-2377. 


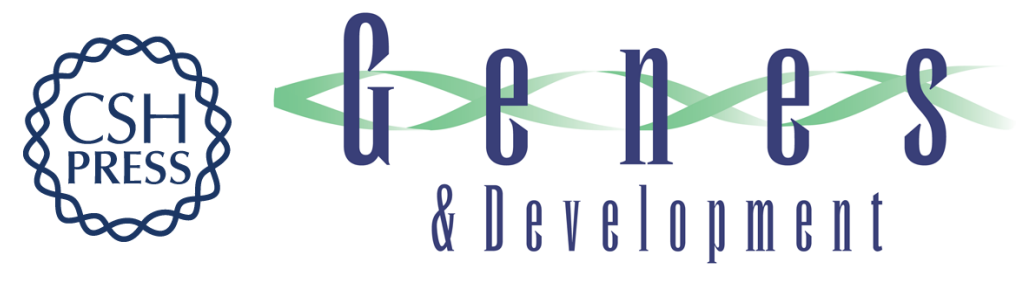

\section{Replication fork stalling and cell cycle arrest in UV-irradiated Escherichia coli}

Christian J. Rudolph, Amy L. Upton and Robert G. Lloyd

Genes Dev. 2007, 21:

Access the most recent version at doi:10.1101/gad.417607

Supplemental http://genesdev.cshlp.org/content/suppl/2007/03/19/21.6.668.DC1
Material

References This article cites 39 articles, 15 of which can be accessed free at: http://genesdev.cshlp.org/content/21/6/668.full.html\#ref-list-1

License

Email Alerting Receive free email alerts when new articles cite this article - sign up in the box at the top Service right corner of the article or click here.

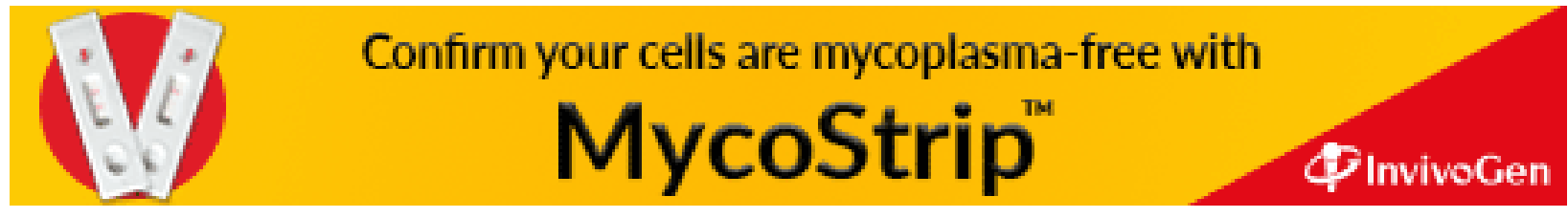

